\title{
NOVEL APPLICATION OF MIXED SOLVENCY CONCEPT IN ECOFRIENDLY QUANTIATIVE ANAL YSIS OF BULK DRUG OF DICLOFENAC SODIUM
}

\author{
Masheer Ahmed Khan*, Prateeti Kaushik, R.K. Maheshwari \\ School of Pharmacy, Devi Ahilya Vishwavidyalaya, Takshshila Campus, Khandwa Road, Indore-452001, India \\ *Corresponding Author's Telephone: +91-9425069821, E-mail: $\underline{\text { masheerak@yahoo.com }}$
}

Received 22 July 2012; Review Completed 28 Aug 2012; Accepted 03 Sep 2012, Available online 15 Sep 2012

\begin{abstract}
'Mixed-solvency ' concept is the phenomenon to increase the solubility of poorly water-soluble drugs in the aqueous solution containing blends of hydrotropic agents, co-solvents and water soluble solutes which may give synergistic enhancement effect on solubility of such drugs. In the present study mixed -solvency concept has been applied for the enhancement of aqueous solubility of a poorly water-soluble drug diclofenec sodium(selected as a model drug) by making blends of randomly selected water-soluble substances from among the hydrotropes (urea, sodium citrate) ; water soluble solutes(PEG4000, PEG6000); and co-solvents(PEG300,PEG400). The aqueous solubility of diclofenac sodium was observed at room temperature in the randomly selected blends of different combinations keeping total concentration $30 \% \mathrm{w} / \mathrm{v}$ constant. Quantitative analysis of bulk drug diclofenec sodium was done by u.v. spectrophotometric estimation at $\lambda$ max at $276 \mathrm{~nm}$ in concentration range of $15-$ $90 \mu \mathrm{g} / \mathrm{ml}$. The results suggests significant enhancement in the solubility of the poorly water soluble drug sample containing different combinations of such substances (blends).

Key words: poorly water-soluble drugs, solubility, mixed solvency.
\end{abstract}

\section{INTRODUCTION}

Hydrotropes, co-solvents and water soluble solutes have been observed to enhance the aqueous solubility of poorly water soluble drugs. It has been demonstrated that synergistic effect can be obtained by mixed solvency concept. The use of hydrotropy can be utilized in titrimetric and spectrophometric estimation of a large number of poorly water soluble drug substances. The mixed solvency approach discourages the use of organic solvents in large concentration (which may prove toxic) for development of a dosage forms. A number of solubilizers may be taken in small concentration curtailing their toxic levels and shows significant improvement in the solubility of the of poorly water soluble drugs ${ }^{1-9}$.

\section{MATERIALS UNDER METHODS}

Gift sample of drug Diclofenac sodium was procured from $\mathrm{M} / \mathrm{s}$ Aerrow pharmaceuticals, Indore, M.P. All the chemicals and solvents used were of analytical grade. Distilled water was used to prepare the solutions of solubilizers. A spectrophotometer (UV-1700 Shimadzo) was used for quantitative analysis.

\section{METHODS}

Preparation of calibration curve of Diclofenac sodium: 40 $\mathrm{mg}$ of Diclofenac sodium was accurately weighed and transferred to $50 \mathrm{ml}$ volumetric flask. To this $40 \mathrm{ml}$ of distilled water was added. The flask was shaken to solubilize the drug and volume was made upto the mark with distilled water. The stock solution was further diluted with distilled water to obtain various dilutions containing between $15-90 \mu \mathrm{g} / \mathrm{ml}$. Absorbance was noted at $276 \mathrm{~nm}$ against reagent blanks to get the calibration curve. The Solubilityof diclofenec sodium in distilled water was observed and shown in Table (1).

\section{ANALYSIS OF DICLOFENAC SODIUM (API) BY} PROPOSED METHOD:
A blend ( $30 \% \mathrm{w} / \mathrm{v}$ constant) of solubilizers was prepared by using varying concentrations of the solvents as shown below for Blends (1-4)

\section{Blend 1}

\begin{tabular}{|l|l|}
\hline Solvent & Concentration \\
\hline Urea & $7.5 \%$ \\
\hline PEG 4000 & $7.5 \%$ \\
\hline Sodium acetate & $7.5 \%$ \\
\hline PEG 300 & $7.5 \%$ \\
\hline
\end{tabular}

Blend 2

\begin{tabular}{|l|l|}
\hline Solvent & Concentration \\
\hline Urea & $10 \%$ \\
\hline PEG 6000 & $8 \%$ \\
\hline PEG4000 & $6 \%$ \\
\hline PEG 400 & $6 \%$ \\
\hline
\end{tabular}

Blend 3

\begin{tabular}{|l|l|}
\hline Solvent & Concentration \\
\hline Ureat & $10 \%$ \\
\hline Sodium acetate & $4 \%$ \\
\hline PEG 6000 & $12 \%$ \\
\hline PEG 300 & $4 \%$ \\
\hline
\end{tabular}

Blend 4

\begin{tabular}{|l|l|}
\hline Solvent & Concentration \\
\hline Urea & $12 \%$ \\
\hline PEG300 & $8 \%$ \\
\hline PEG400 & $5 \%$ \\
\hline Sodium acetate & $5 \%$ \\
\hline
\end{tabular}


Khan et al

Journal of Drug Delivery \&

Bulk drug was first dissolved in $10 \mathrm{ml}$ of blend 1.The solution was vigorously shaken for a definite time with regular intervals until a supersaturated solution is obtained. The resulting solution was diluted upto $1000 \mathrm{ml}$ with the blend. Absorbance of this solution was noted at $276 \mathrm{~nm}$ against the solvent blend. The same procedure was followed with the other blends (2-4) and absorbance was noted at the same wavelength. The corresponding concentration gives the solubility of the drug and thus the enhanced solubility of the drug was calculated by comparing the solubility of the drug in water.

\section{RESULTS AND DISCUSSION}

The results obtained are shown in Table (1) for Solubility of diclofenec sodium in water as well as in Table (2) Solubility of diclofenec sodium in different blends (1-4). It

Table 2: Solubility in blends

\begin{tabular}{|c|c|c|c|}
\hline S.No. & Blend number & Absorbance & Saturated solubility \\
\hline 1 & Blend 1 & 1.176 & $110 \mu \mathrm{g} / \mathrm{ml}$ \\
\hline 2 & Blend 2 & 1.463 & $154 \mu \mathrm{g} / \mathrm{ml}$ \\
\hline 3 & Blend 3 & 1.692 & $185 \mu \mathrm{g} / \mathrm{ml}$ \\
\hline 4 & Blend 4 & 1.731 & $192 \mu \mathrm{g} / \mathrm{ml}$ \\
\hline
\end{tabular}

These results demonstrate the principle of mixed-solvency concept that water-soluble substances whether hydrotropes or solvents or water-soluble solids combined randomly gives a desired solubility for a poorly water-soluble drugs. The results also suggests that in developing liquid dosage forms, blends of solubilizers can be employed to reduce the toxicities of solubilizers by reducing the individual concentration of solubilizers ( instead of employing one solubilizer in higher concentration which may be toxic for same solubility enhancement).Blends of water soluble substances can be made in safe level of concentrations of individual solubilizer to give a concentrated solution to act as solubilizing system for development of liquid syrups or topical solutions or injections etc.

\section{REFERENCES}

1. Maheshwari, RK., Solubilization of ibuprofen by mixed solvency approach, The Indian Pharmacist, 2009, vol VIII,No.87;81-83.

2. Maheshwari RK, Chavada V, Shahoo K, and Varghese S., Analysis of bulk sample of salicylic acid by application of hydrotropic solubilization method, Indian journal of pharmaceutical science 2008; 70(6): 823-825.

3. Maheshwari RK, Deswal S, Tiwari D, Ali N, Pothen B, Jain S. Novel spectrophotometric estimation of frusemide using hydrotropic solubilization phenomenon, Indian Journal of Pharmaceutical Science 2007; 69(6): 822-824.

4. Maheshwari, RK., Chaturvedi,SC.,and Jain,NK., Application of hydrotropy in spectrophotometric determination of pharmaceutical dosage forms, Indian drugs, 42; 2005,760763.

5. Maheshwari RK, Chavada V, Shahoo K, and Varghese S.,Novel application of hydrotropic solubilization in the is evident that there was improvement in the solubility of diclofenac sodium in $(30 \%$ blend $)$ containing different combinations of urea, PEG4000, PEG6000, PEG300, PEG400 and sodium acetate. On comparing Table-1 and Table-2, the drug solubility was found to be enhanced by $1.83,2.57,3.08$ and 3.2 folds with blend-1, 2, 3 and 4 respectively. The greatest enhancement in solubility was observed in case of Blend 4 and least in case of Blend 1.

Table 1: Solubility in distilled water

\begin{tabular}{|l|l|l|}
\hline S. N. & Solvent system (Distilled water) & Absorbance \\
\hline 1 & $30 \mu \mathrm{g} / \mathrm{ml}$ & 0.72 \\
\hline 2 & $60 \mu \mathrm{g} / \mathrm{ml}$ & 0.86 \\
\hline 3 & $90 \mu \mathrm{g} / \mathrm{ml}$ & 0.98 \\
\hline
\end{tabular}

\section{CONCLUSION}

The solubility of the Diclofenac Sodium containing different combinations of urea, PEG4000, PEG6000, PEG300, PEG400 and sodium acetate was enhanced significantly, using this mixed-solvency approach. Therefore the results suggest that mixed -solvency approach for the enhancement of solubility of poorly watersoluble sample drug can also be used successfully for other poorly-water soluble drugs.

\section{ACKNOWLEDGEMENT}

The author is thankful to $\mathrm{M} / \mathrm{s}$ Aerrow pharmaceuticals, Indore, M.P.for providing gift sample of drugs. spectrophotmetric analysis of diclofenec sodium in solid dosage forms, Asian Journal of Pharmaceutics; 2006, volume1, Issue1, 30-33.

6. Indian Pharmacopoeia, Controller of Publications, Delhi, 1996, Vol1, 388.

7. Etman,MA and Nada, AH., Hydrotropic and cosolvent solubilization of indomethacin, Acta Pharma., 49,1999,291298.

8. Maheshwari RK, Deswal S, Aher R, Wanare G, Jawade S, Indurkhya A, Jagwani. Ibuprofen Sodium: A Novel Hydrotropic Agent For Estimation of Poorly Water-Soluble Drugs, Journal of Applied Chemical Research 2009; 10: 5660.

9. Patel R, Patel N, Patel N M, Patel M ., A novel approach for dissolution enhancement of Ibuprofen by preparing floating granules, Int. J. Res. Pharm. Sci. Vol-1, Issue-1, 57-64, 2010. 